\title{
Calcimimetics in CKD_results from recent clinical studies
}

\author{
Georg Schlieper • Jürgen Floege
}

Received: 20 March 2008/Revised: 3 May 2008 / Accepted: 5 May 2008/Published online: 2 July 2008

(C) IPNA 2008

\begin{abstract}
Secondary hyperparathyroidism (sHPT) is a frequent complication in patients with chronic kidney disease (CKD) and a known contributor to the development of vascular calcification and renal osteodystrophy (CKDBMD). Secondary hyperparathyroidism is also related to increased cardiovascular mortality in CKD patients. With the discovery that molecules can modulate the calciumsensing receptor (CaR) of the parathyroid gland, new treatment options are now available to control sHPT. Calcimimetics activate the $\mathrm{CaR}$ and-by increasing its sensitivity to calcium - can effectively decrease parathyroid hormone (PTH) secretion. Calcimimetic treatment with cinacalcet has resulted in an effective lowering of PTH levels in both animal and clinical studies. Most clinical studies have been performed in dialysis patients, and only a few studies have been carried out in patients with CKD stage $3 \& 4$ and renal transplant patients. In haemodialysis patients with SHPT, cinacalcet treatment could increase the number of patients achieving National Kidney Foundation Kidney Disease Outcomes Quality Initiative targets (PTH, calcium, phosphate) compared to standard therapy. In stage 3 and 4 CKD patients, cinacalcet has been reported to reduce PTH levels, however, at the expense of increasing phosphate serum levels. Several small studies have reported that calcimimetics reduced PTH levels and hypercalcaemia
\end{abstract}

J. Floege has received lecture and consulting fees from Amgen and is performing collaborative studies both clinically and experimentally with Amgen.

G. Schlieper $(\bowtie) \cdot$ J. Floege

Department of Nephrology and Clinical Immunology,

RWTH University Hospital Aachen,

Pauwelsstr. 30,

52074 Aachen, Germany

e-mail: gschlieper@ukaachen.de after renal transplantation. In addition, two studies on paediatric dialysis patients with sHPT reported effective PTH lowering. This review summarizes recent clinical studies with cinacalcet treatment in CKD patients.

Keywords Calcimimetics . Cinacalcet .

Chronic kidney disease . End-stage renal disease .

Pediatric patients $\cdot$ Review $\cdot$ Secondary hyperparathyroidism

\section{Background}

Secondary hyperparathyroidism (sHPT) frequently develops during stages 3 and 4 of chronic kidney disease (CKD3/4). Increased serum levels of intact parathyroid hormone (PTH) have been associated with cardiovascular calcifications, morbidity and mortality in dialysis patients. Prolonged hypocalcaemia, hyperphosphataemia, low calcitriol and elevated FGF-23 levels all contribute to increased PTH synthesis and secretion. Phosphate retention as well as increased FGF-23 levels inhibit the activity of the $1 \alpha$ hydroxylase, which contributes to decreased calcitriol synthesis and constitutes an additional indirect mechanism by which they feed into elevated PTH synthesis. Moreover, the numbers of calcium-sensing receptors $(\mathrm{CaR})$ and vitamin $D$ receptors (VDR) are lower in CKD patients, resulting in a decreased sensitivity of the parathyroid gland to both serum calcium changes and calcitriol. The CaR is responsible for calcium-mediated signalling in parathyroid cells and plays a central role in the regulation of synthesis and secretion of PTH. Calcimimetics activate the CaR by mimicking or potentiating the inhibitory effects of extracellular calcium on parathyroid cells (Fig. 1). This leftward shift in the set point for calcium-regulated PTH secretion by calcimimetics leads to a reduction in PTH secretion. Calcimimetic compounds 


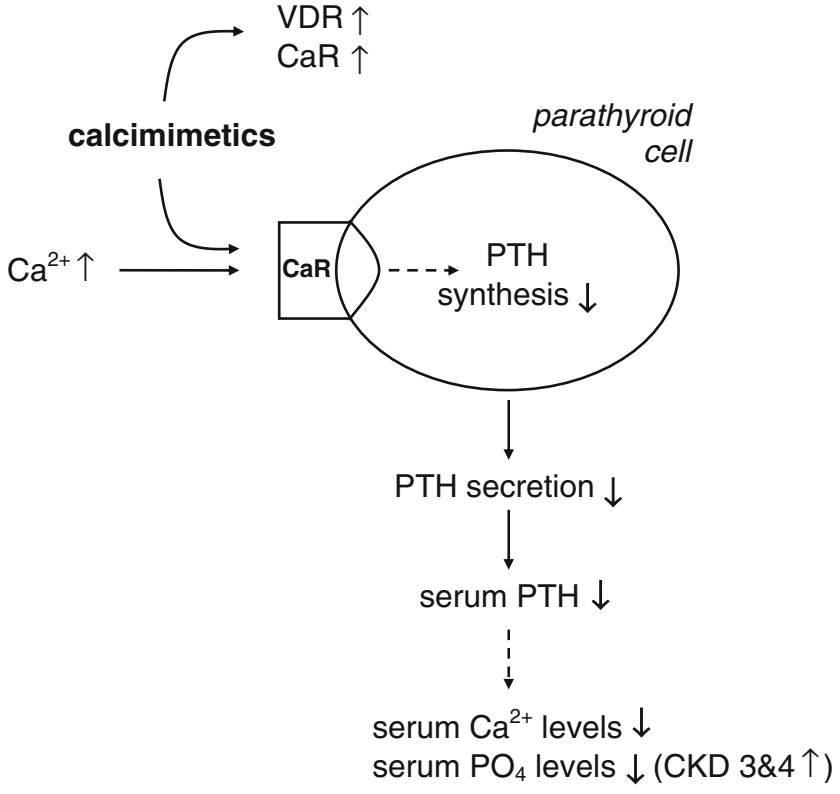

Fig. 1 Calcimimetics act on the calcium-sensing receptor $(\mathrm{CaR})$ by mimicking and/or potentiating the effects of calcium. Increased serum calcium $\left(\mathrm{Ca}^{2+}\right)$ levels activate the $\mathrm{CaR}$ of the parathyroid cell, which leads - via intracellular signalling mechanisms - to decreased parathyroid hormone $(P T H)$ synthesis and secretion. Calcimimetics potentiate the effect of serum calcium and thus can lower serum calcium and serum phosphate $\left(\mathrm{PO}_{4}\right)$ levels in dialysis patients with secondary hyperparathyroidism. Note that calcimimetics can decrease serum phosphate levels only in dialysis patients but not in patients with stage 3 and 4 chronic kidney disease (CKD $3 \& 4$ ) or renal transplant patients. There is also experimental evidence that calcimimetics can increase the numbers of both the $\mathrm{CaR}$ and vitamin $\mathrm{D}$ receptors $(V D R)$ in parathyroid cells

can be either inorganic (e.g. $\mathrm{Mg}^{2+}$ ) or organic molecules (e.g. spermine) or phenylalkylamine derivatives (e.g. cinacalcet). Traditionally, secondary hyperparathyroidism (sHPT) has been treated with calcium and vitamin D therapy plus phosphate binders; however, with these interventions, only a few patients achieved the targetsespecially all of the targets - of the National Kidney Foundation Kidney Disease Outcomes Quality Initiative (KDOQI). Thus, the introduction of cinacalcet as a calcimimetic compound offers new therapeutic options to control sHPT in CKD patients.

\section{Studies of cinacalcet in dialysis patients with SHPT}

Studies assessing biochemical endpoints

It has been possible to demonstrate the safety and efficacy of cinacalcet treatment of SHPT in dialysis patients in controlled trials despite standard therapy with active vitamin D and phosphate binders as appropriate (Table 1) [1-4]. Of note, cinacalcet treatment did not only result in a marked decrease in serum PTH but also in significant reductions in serum calcium, phosphate and the calciumphosphate product. A meta-analysis revealed an average reduction in PTH of $290 \mathrm{pg} / \mathrm{mL}$, in serum calcium of $0.85 \mathrm{mg} / \mathrm{dL}$, in serum phosphate of $0.29 \mathrm{mg} / \mathrm{dL}$ and in the calcium-phosphate product of $7.90 \mathrm{mg}^{2} / \mathrm{dL}^{2}$ [5]. The early decrease in serum calcium, phosphate and the calciumphosphate product may be interpreted as the analogue of a "hungry bone" after parathyroidectomy, where the bone avidly incorporates calcium and phosphate and thus lowers serum calcium and phosphate levels. However, it is notable that in a long-term study, cinacalcet did lead to persistent reductions of the calcium-phosphate product [6] under conditions when a "hungry bone" can no longer be implicated.

A retrospective analysis could demonstrate that cinacalcet treatment increased the percentage of patients achieving the KDOQI targets [7]. In this study, data of three placebocontrolled, double-blind, 26-week studies with similar design were combined. A total of 1136 subjects on dialysis were randomized to receive traditional therapy plus cinacalcet or placebo. Cinacalcet intake was titrated from $30 \mathrm{mg}$ to $180 \mathrm{mg}$ per day. The number of patients achieving both KDOQI targets for phosphate and calcium and PTH levels below $300 \mathrm{pg} / \mathrm{mL}$ increased significantly from 6 to $41 \%$ [7]. The OPTIMA study confirmed these data in a prospective fashion [8]. In this latter study, 552 patients were randomized to conventional treatment or cinacalcet. The primary endpoint, i.e. the proportion of patients with mean PTH levels below $300 \mathrm{pg} / \mathrm{mL}$, could be achieved in $71 \%$ of the patients in the cinacalcet group versus $22 \%$ in the control group [8]. A recent Japanese study also confirmed the effect of cinacalcet on PTH lowering but reported a lower dosage of cinacalcet needed to achieve the PTH target in that Asian population [9]. First results of the ECHO study, a European observational study in 1800 haemodialysis patients with sHPT, confirmed the results of the controlled studies with cinacalcet treatment [10]. After 12 months of treatment with cinacalcet, PTH levels could be reduced by $49 \%$ and the calcium-phosphate product by $17 \%$. Again, the dosage of cinacalcet necessary to achieve this appeared to be lower than in the controlled studies, with most patients ingesting 30 or $60 \mathrm{mg}$ cinacalcet daily [10].

Two studies investigated the effects of cinacalcet added to low doses of vitamin $\mathrm{D}$ in dialysis patients. In the openlabel TARGET study, 444 haemodialyis patients were treated with cinacalcet and around $80 \%$ of the patients were on vitamin $\mathrm{D}$ treatment, which was reduced in the second part of the study [11]. Cinacalcet plus low-dose vitamin $\mathrm{D}$ treatment was able to improve KDOQI targets [11]. Another study investigated the combination of cinacalcet with a fixed low-dose vitamin D therapy versus 


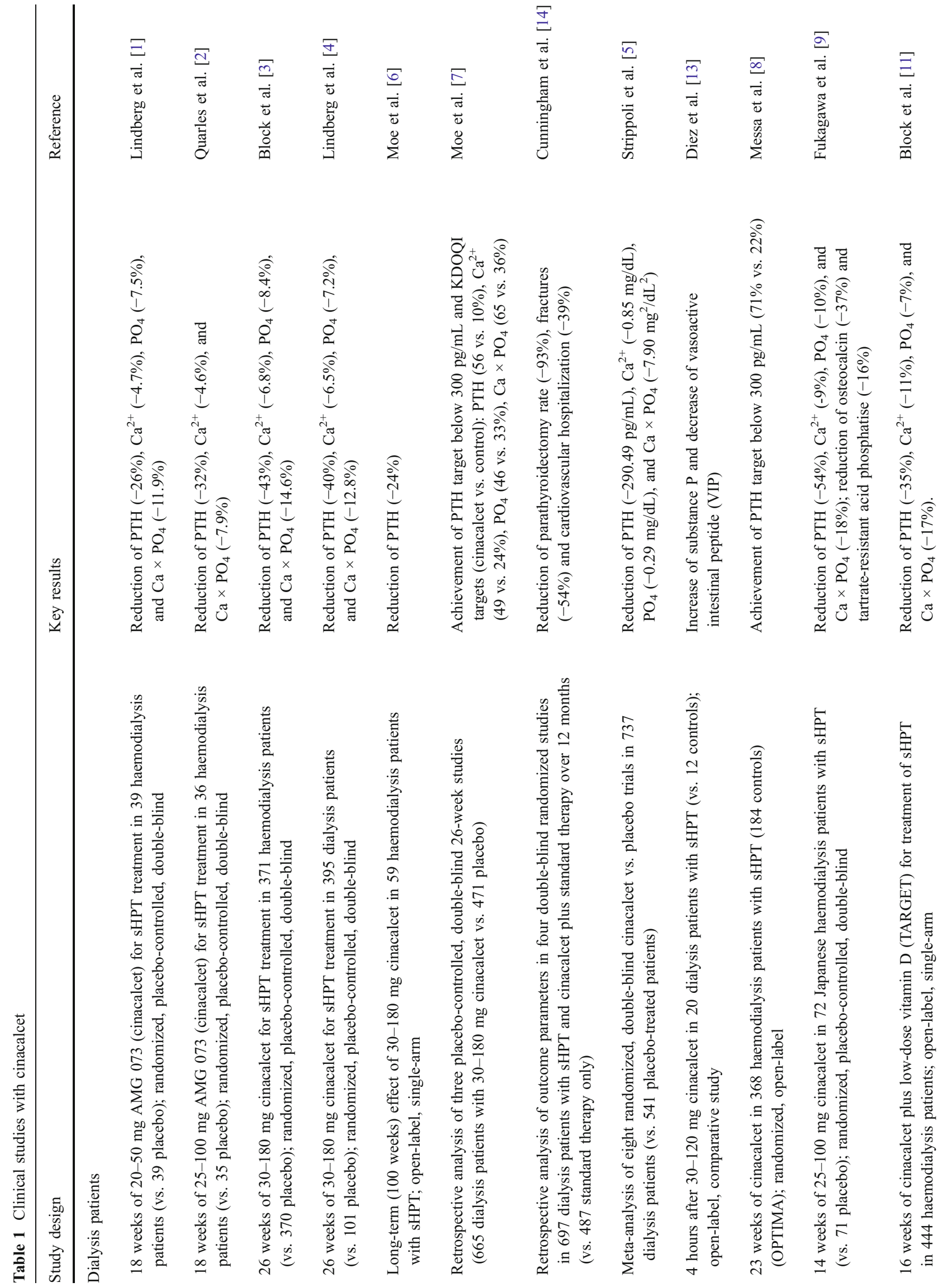




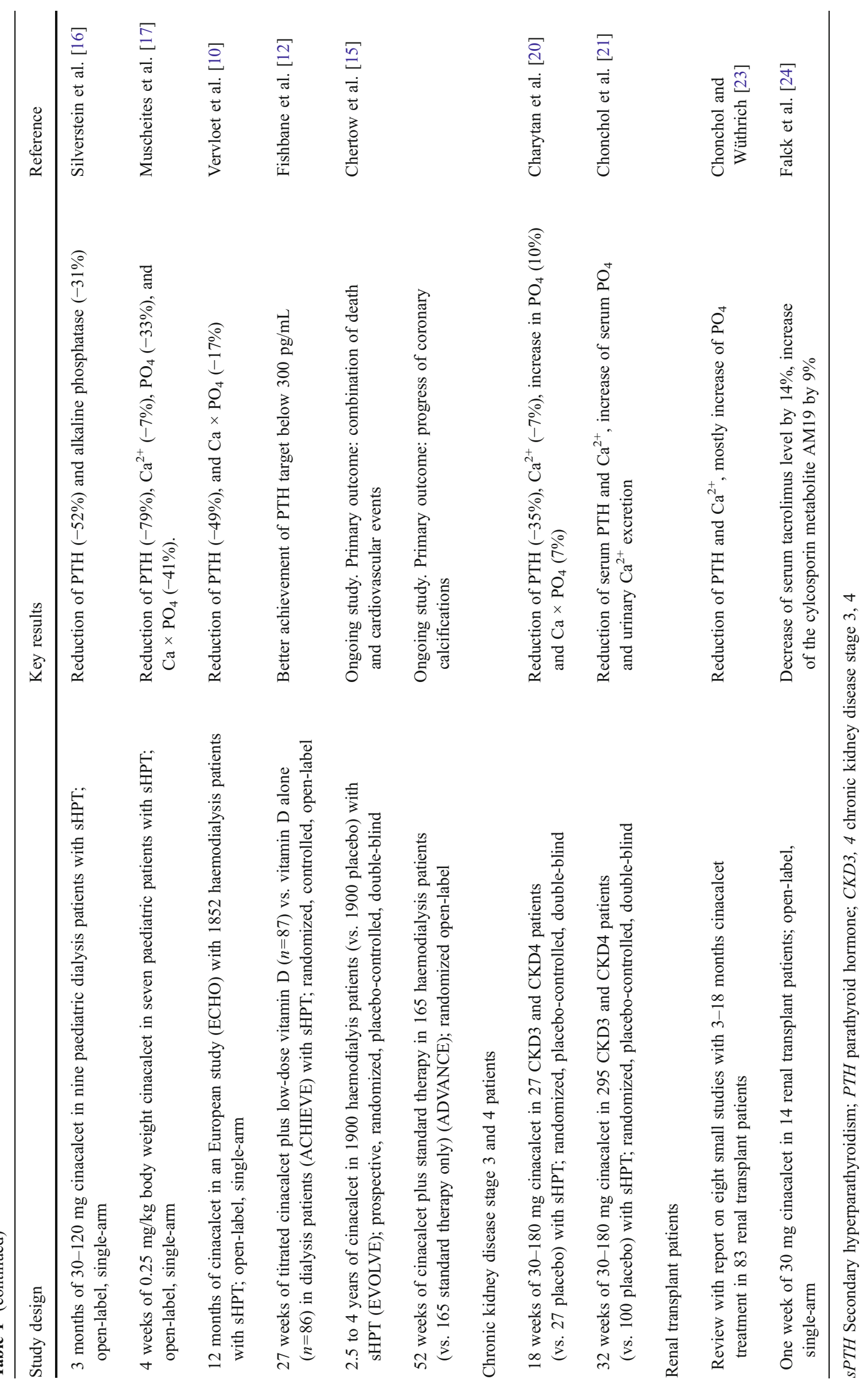


vitamin $\mathrm{D}$ alone (where flexible dosing was allowed) in 173 dialysis patients (ACHIEVE) [12]. In this study, the fixed combination of cinacalcet plus low-dose vitamin D resulted in an effective PTH lowering when compared to vitamin D alone. However, in both of the studies, no direct comparison of cinacalcet without vitamin D versus cinacalcet plus vitamin $\mathrm{D}$ was made. Thus, it can only be concluded that cinacalcet plus vitamin D is a feasible therapeutic strategy, but the advantage of vitamin $\mathrm{D}$ added to cinacalcet has yet to be proven.

Side effects of cinacalcet are most commonly related to gastrointestinal disturbances and include nausea, vomiting, diarrhoea and loss of appetite. Cinacalcet treatment causes only minimal changes in gut hormones [13]. Whether the decrease in vasoactive intestinal peptide (VIP) or the increase in substance $\mathrm{P}$ at $4 \mathrm{~h}$ after cinacalcet ingestion is responsible for the unwanted symptoms remains to be determined. Alternatively, these side effects may be related to cinacalcet binding to the calcium-sensing receptor in the gut, i.e. direct cinacalcet effects.

\section{Studies assessing clinical endpoints}

As increased PTH levels are associated with increased mortality, it is of interest to determine whether cinacalcet treatment can improve clinical outcomes. With the aim of assessing the efficacy of cinacalcet treatment, Cunningham et al. [14] performed a retrospective analysis of various intervention studies that primarily looked at biochemical parameters (see above). In this analysis, pooled data from four randomized controlled studies were evaluated, and several outcome parameters were measured in more than 1400 haemodialysis patients at 6-12 months: parathyroidectomy, fractures, hospitalization, mortality and self-reported quality of life. Cinacalcet treatment plus standard care led to a significantly reduced rate of parathyroidectomies (-93\%) and fractures $(-54 \%)$ when compared to the group with standard care alone. While the number of all-cause hospitalizations did not differ between the two groups, patients in the cinacalcet group had significantly reduced cardiovascular (CV)-related hospitalizations (-39\%). However, this benefit became most notable during the later, open-label phase of the studies and when patient numbers had dropped markedly. This outcome thus represents an interesting pilot observation, which will require confirmation in adequate prospective studies. In terms of quality of life, patients randomized to cinacalcet treatment reported an improvement in physical function but not in the other domains [14]. Finally, over the course of the short-term observation, there was no significant difference in mortality in the group treated with cinacalcet compared to the standard treatment group.

Following these above pilot studies, the Evaluation of Cinacalcet $\mathrm{HCl}$ Therapy to Lower CV Events (EVOLVE) study was initiated. EVOLVE is a randomized placebocontrolled trial investigating the effect of cinacalcet treatment on mortality and CV events [15]. In this worldwide phase 3 randomized, double-blind, controlled clinical trial, approximately 3800 haemodialyis patients with sHPT have been assigned to cinacalcet or placebo in addition to traditional therapy. Recruitment finished in early 2008, and the study, which is event-driven, is expected to last a further 2.5 years. The primary composite endpoint is time to allcause mortality or the first occurrence of a non-fatal CV event (myocardial ischaemia or infarction, heart failure, or peripheral vascular event). Cinacalcet will be titrated between 30 and $180 \mathrm{mg} /$ day based on PTH concentrations, and flexible use of active vitamin $\mathrm{D}$ derivatives and phosphate binders will be permitted in both treatment groups. The aim of a second randomized world-wide trial is to investigate whether cinacalcet can slow down the progression of coronary artery calcification in haemodialysis patients (ADVANCE trial $=\mathrm{A}$ randomizeD VAscular calcificatioN study to evaluate the effects of CinacalcEt). In this study, approximately 330 haemodialysis patients will be investigated over the course of 1 year, with patients assigned to either cinacalcet in combination with low-dose vitamin D or standard therapy.

Taken together, cinacalcet has been shown to reduce not only PTH levels effectively but also to lower serum calcium and phosphate levels in CKD patients on dialysis. Whether these changes will lead to reduced morbidity or a survival benefit in dialysis patients is currently under investigation.

\section{Studies in paediatric dialysis patients with SHPT}

As the problem of sHPT is not limited to adult CKD patients, calcimimetics also provide a therapeutic option in the treatment of sHPT in paediatric dialysis patients. Two open-label single-arm studies reported in this issue of the journal investigated cinacalcet treatment in nine and seven paediatric patients with end stage renal disease (ESRD) and sHPT, respectively $[16,17]$. The young patients (range $7.5-$ 17.5 and 1.1-19 years, respectively) were both on haemodialysis and peritoneal dialysis regimens. In these studies, cinacalcet treatment resulted in a $61 \%$ and $79 \%$ decline of serum PTH levels, respectively. This decrease in PTH seems to be more pronounced in paediatric patients when compared to adults (Table 1). The cinacalcet dosage was therefore reduced to $0.25 \mathrm{mg} / \mathrm{kg}$ body weight in the second study [17], which is significantly lower that the usual starting dose of $30 \mathrm{mg}$ in adults. It is possible that even lower starting dosages than the suggested $0.25 \mathrm{mg} / \mathrm{kg}$ should be considered (e.g. $0.15 \mathrm{mg} / \mathrm{kg}$ body weight).

Calcimimetics do have the potential to interfere with growth during adolescence (epiphyseal chondrocytes express the CaR). However, at least one experimental study was 
unable to find a significant effect of cinacalcet on longitudinal growth in uremic rats [18]. Another concern associated with treating adolescent children with calcimimetics is that lower testosterone levels have been reported recently in adult patients on cinacalcet treatment [19].

Taken together, cinacalcet seems to be equally effective in children as in adults; however, studies investigating longterm consequences of cinacalcet therapy in adolescents need to be performed.

\section{Studies of cinacalcet in CKD 3 and 4 patients with sHPT}

Since sHPT often develops in stages 3 and 4 of CKD, an attractive option is to start cinacalcet treatment in earlier stages with the aim of controlling SHPT effectively before advanced or tertiary hyperparathyroidism develops. One preliminary study reported that cinacalcet can efficiently treat sHPT in CKD patients not receiving dialysis [20]. In this double-blind placebo-controlled study, cinacalcet treatment was evaluated in 54 patients with CKD 3 and 4. Cinacalcet treatment decreased PTH levels by approximately $35 \%$ and lowered serum calcium levels by $7 \%$, whereas the levels of serum phosphate and the calcium-phosphate product increased by approximately 10 and $7 \%$, respectively [20]. A larger double-blind randomized study with nearly $400 \mathrm{CKD}$ 3 and 4 patients recently confirmed these results and reported an effective reduction in serum PTH and calcium levels while, again, phosphate levels increased with cinacalcet treatment [21]. Whether such an increase in serum phosphate levels bears a risk for vascular calcification, or other adverse outcomes, remains to be determined.

\section{Studies of cinacalcet in renal transplant patients with persistent SHPT}

Hyperparathyroidism frequently persists after successful renal transplantation; in particular, pronounced phosphaturia with resulting hypophosphataemia are frequent observations early after renal transplantation. Oral or parenteral phosphate replacement in such instances may contribute to intra-graft calcifications, a recently recognized cause of inferior graft survival [22]. Cinacalcet provides an attractive alternative therapeutic option in this latter case, but also for patients with persistent hyperparathyroidism long after transplantation. The results from eight small studies assessing the off-label use of cinacalcet in a maximum of 18 transplant patients were recently summarized by Chonchol and Wüthrich [23]. In all of these studies, relatively low cinacalcet doses were needed (average, $30-40 \mathrm{mg}$ /day) to control hyperparathyroidism. Therapy with cinacalcet led to
PTH and serum calcium decreases while phosphate serum levels were mostly upregulated without adversely affecting graft function [23]. As cinacalcet may interact with immunosupressants, a recent study with 14 transplanted patients investigated the effect of cinacalcet on serum levels of cyclosporine, tacrolimus and mycophenolate [24]. Cinacalcet treatment induced a $14 \%$ decrease in tacrolimus levels while cyclosporine and mycophenolate levels were not significantly altered. The level of the cyclosporine metabolite AM19 was increased by $9 \%$, and this increase was paralleled by a small but significant reduction in glomerular filtration rate (GFR) [24]. Thus, immunosuppressant levels and graft function need to be monitored closely when cinacalcet treatment has been initiated or altered in transplanted patients.

\section{Other potential indications for cinacalcet in CKD patients}

In addition to the treatment of sHPT, cinacalcet may be used to treat other clinical conditions in CKD patients. The most commonly recommended approach to treating primary hyperparathyroidism in symptomatic patients is parathyroidectomy. Even asymptomatic patients may be considered for parathyroidectomy when they meet criteria, such as young age, increased serum calcium levels, increased urinary calcium excretion, reduced bone density or decreased renal function [25]. In a multicentre, randomized, double-blind, placebo-controlled study with 78 patients, cinacalcet normalized serum calcium and reduced PTH in patients with primary hyperparathyroidism. As these effects were maintained with long-term treatment, cinacalcet may be an effective, non-surgical approach for the management of primary hyperparathyroidism [26]. Very recently, a small study on four patients was able to demonstrate that cinacalcet can lower PTH levels after unsuccessful parathyroidectomy [27]. Another condition for which calcimimetics can be used is parathyroid carcinoma. In patients with inoperable parathyroid carcinoma, cinacalcet was shown to effectively lower serum calcium levels in about two thirds of the patients [28]. In this study with 29 patients, PTH levels could only be slightly decreased; however, this result demonstrates that calcimimetics offer a therapeutic option for calcium lowering in patients with parathyroid carcinoma when other treatment options fail.

Finally, the gastrointestinal, in particular colonic, expression of the CaR may be of therapeutic interest in completely different clinical scenarios. Preliminary evidence shows that the chemopreventive action of calcium and calcitriol in colon cancer is mediated - at least in part - through the CaR [29] and that receptor agonists were able to reverse cholera toxin and shiga toxin-induced secretory diarrhoea [30]. Moreover, 
it has been shown in animal experiments that calcimimetics may exert beneficial effects on blood pressure in uremia and may ameliorate kidney damage in subtotally nephrectomized rats [31-33]. Thus, in the future, clinical indications for calcimimetics may reach far beyond the control of PTH secretion.

\section{References}

1. Lindberg JS, Moe SM, Goodman WG, Coburn JW, Sprague SM, Liu W, Blaisdell PW, Brenner RM, Turner SA, Martin KJ (2003) The calcimimetic AMG 073 reduces parathyroid hormone and calcium $\mathrm{x}$ phosphorus in secondary hyperparathyroidism. Kidney Int 63:248-254

2. Quarles LD, Sherrard DJ, Adler S, Rosansky SJ, McCary LC, Liu W, Turner SA, Bushinsky DA (2003) The calcimimetic AMG 073 as a potential treatment for secondary hyperparathyroidism of endstage renal disease. J Am Soc Nephrol 14:575-583

3. Block GA, Martin KJ, de Francisco AL, Turner SA, Avram MM, Suranyi MG, Hercz G, Cunningham J, Abu-Alfa AK, Messa P, Coyne DW, Locatelli F, Cohen RM, Evenepoel P, Moe SM, Fournier A, Braun J, McCary LC, Zani VJ, Olson KA, Drueke TB, Goodman WG (2004) Cinacalcet for secondary hyperparathyroidism in patients receiving hemodialysis. N Engl J Med 350:1516-1525

4. Lindberg JS, Culleton B, Wong G, Borah MF, Clark RV, Shapiro WB, Roger SD, Husserl FE, Klassen PS, Guo MD, Albizem MB, Coburn JW (2005) Cinacalcet $\mathrm{HCl}$, an oral calcimimetic agent for the treatment of secondary hyperparathyroidism in hemodialysis and peritoneal dialysis: a randomized, double-blind, multicenter study. J Am Soc Nephrol 16:800-807

5. Strippoli GF, Palmer S, Tong A, Elder G, Messa P, Craig JC (2006) Meta-analysis of biochemical and patient-level effects of calcimimetic therapy. Am J Kidney Dis 47:715-726

6. Moe SM, Cunningham J, Bommer J, Adler S, Rosansky SJ, Urena-Torres P, Albizem MB, Guo MD, Zani VJ, Goodman WG, Sprague SM (2005) Long-term treatment of secondary hyperparathyroidism with the calcimimetic cinacalcet $\mathrm{HCl}$. Nephrol Dial Transplant 20:2186-2193

7. Moe SM, Chertow GM, Coburn JW, Quarles LD, Goodman WG, Block GA, Drueke TB, Cunningham J, Sherrard DJ, McCary LC, Olson KA, Turner SA, Martin KJ (2005) Achieving NKF-K/ DOQI bone metabolism and disease treatment goals with cinacalcet $\mathrm{HCl}$. Kidney Int 67:760-771

8. Messa P, Macario F, Yaqoob M, Bouman K, Braun J, von Albertini B, Brink H, Maduell F, Graf H, Frazao JM, Bos WJ, Torregrosa V, Saha H, Reichel H, Wilkie M, Zani VJ, Molemans B, Carter D, Locatelli F (2008) The OPTIMA study: assessing a new cinacalcet (Sensipar/Mimpara) treatment algorithm for secondary hyperparathyroidism. Clin J Am Soc Nephrol 3:36-45

9. Fukagawa M, Yumita S, Akizawa T, Uchida E, Tsukamoto Y, Iwasaki M, Koshikawa S (2008) Cinacalcet (KRN1493) effectively decreases the serum intact PTH level with favorable control of the serum phosphorus and calcium levels in Japanese dialysis patients. Nephrol Dial Transplant 23:328-335

10. Vervloet M, Malberti F, Ashman N, Rix M, Ureña P, Fouque D, Baños A, Harris C, Zani W, Neyer U (2007) Cinacalcet (Mimpara/Sensipar) increased KDOQI goal achievement in "real-world" clinical practice (ECHO study). In: Renal Week 2007 (American Society of Nephrology Annual Meeting). Abstract SU-FC098. San Francisco

11. Block GA, Zeig S, Sugihara J, Chertow GM, Chi EM, Turner SA, Bushinsky DA (2008) Combined therapy with cinacalcet and low doses of vitamin D sterols in patients with moderate to severe secondary hyperparathyroidism. Nephrol Dial Transplant doi:10.1093/ndt/gfn026

12. Fishbane S, Wetmore J, Moustafa M, Martinez C, Ling X, Turner S, Charytan C (2007) Treatment with cinacalcet $\mathrm{HCl}$ and concurrent low-dose vitamin D improved management of secondary hyperparathyroidism (SHPT) compared with vitamin D alone. In: Renal Week 2007 (American Society of Nephrology Annual Meeting). Abstract SU-FC100. San Francisco

13. Diez JJ, Miguel JL, Codoceo R, Iglesias P, Bajo MA, Sanchez C, Del Peso G, Gil F, Martinez-Ara J, Gancedo PG, Selgas R (2008) Effects of cinacalcet on gastrointestinal hormone release in patients with secondary hyperparathyroidism undergoing dialysis. Nephrol Dial Transplant 23:1387-1395

14. Cunningham J, Danese M, Olson K, Klassen P, Chertow GM (2005) Effects of the calcimimetic cinacalcet $\mathrm{HCl}$ on cardiovascular disease, fracture, and health-related quality of life in secondary hyperparathyroidism. Kidney Int 68:1793-1800

15. Chertow GM, Pupim LB, Block GA, Correa-Rotter R, Drueke TB, Floege J, Goodman WG, London GM, Mahaffey KW, Moe SM, Wheeler DC, Albizem M, Olson K, Klassen P, Parfrey P (2007) Evaluation of cinacalcet therapy to lower cardiovascular events (EVOLVE): rationale and design overview. Clin J Am Soc Nephrol 2:898-905

16. Silverstein DM, Kher KK, Moudgil A, Khurana M, Wilcox J, Moylan K (2008) Cinacalcet is efficacious in pediatric dialysis patients. Pediatr Nephrol doi:10.1007/s00467-007-0742-5

17. Muscheites J, Wigger M, Drueckler E, Fischer DC, Kundt G, Haffner D (2008) Cinacalcet for secondary hyperparathyroidism in children with end-stage renal disease. Pediatr Nephrol doi:10.1007/s00467-008-0810-5

18. Nakagawa K, Perez EC, Oh J, Santos F, Geldyyev A, Gross ML, Schaefer F, Schmitt CP (2008) Cinacalcet does not affect longitudinal growth but increases body weight gain in experimental uraemia. Nephrol Dial Transplant doi:10.1093/ndt/gfn143

19. U.S.National Library of Medicine 8RPBM2IoHH\&HS (2008) Daily med current medication Information on cinacalcet. Available at: http://dailymed.nlm.nih.gov/dailymed/drugInfocfm?id=6922

20. Charytan C, Coburn JW, Chonchol M, Herman J, Lien YH, Liu W, Klassen PS, McCary LC, Pichette V (2005) Cinacalcet hydrochloride is an effective treatment for secondary hyperparathyroidism in patients with $\mathrm{CKD}$ not receiving dialysis. Am J Kidney Dis 46:58-67

21. Chonchol M, Locatelli F, Abboud H, Charytan C, de Francisco A, Jolly S, Kaplan M, Roger S, Sarkar S, Albizem M, Cheng S, Kubo Y, Block G (2007) A randomized, double-blind, placebocontrolled study of cinacalcet in CKD not on dialysis. In: Renal Week 2007 (American Society of Nephrology Annual Meeting). Abstract SA-PO867. San Francisco

22. Gwinner W, Suppa S, Mengel M, Hoy L, Kreipe HH, Haller H, Schwarz A (2005) Early calcification of renal allografts detected by protocol biopsies: causes and clinical implications. Am J Transplant 5:1934-1941

23. Chonchol M, Wüthrich RP (2008) Potential future uses of calcimimetics in patients with chronic kidney disease. Nephrol Dial Transplant plus 1:i36-i41

24. Falck P, Vethe NT, Asberg A, Midtvedt K, Bergan S, Reubsaet JL, Holdaas H (2008) Cinacalcet's effect on the pharmacokinetics of tacrolimus, cyclosporine and mycophenolate in renal transplant recipients. Nephrol Dial Transplant 23:1048-1053

25. Bilezikian JP, Silverberg SJ (2004) Clinical practice. Asymptomatic primary hyperparathyroidism. N Engl J Med 350:1746-1751

26. Peacock M, Bilezikian JP, Klassen PS, Guo MD, Turner SA, Shoback D (2005) Cinacalcet hydrochloride maintains long-term normocalcemia in patients with primary hyperparathyroidism. J Clin Endocrinol Metab 90:135-141 
27. Iglesias P, Ais G, Gonzalez A, Tajada P, Arevalo CG, Pardo EF, Diez JJ (2008) Acute and one-year effects of cinacalcet in patients with persistent primary hyperparathyroidism after unsuccessful parathyroidectomy. Am J Med Sci 335:111-114

28. Silverberg SJ, Rubin MR, Faiman C, Peacock M, Shoback DM, Smallridge RC, Schwanauer LE, Olson KA, Klassen P, Bilezikian JP (2007) Cinacalcet hydrochloride reduces the serum calcium concentration in inoperable parathyroid carcinoma. J Clin Endocrinol Metab 92:3803-3808

29. Chakrabarty S, Wang H, Canaff L, Hendy GN, Appelman H, Varani J (2005) Calcium sensing receptor in human colon carcinoma: interaction with $\mathrm{Ca}(2+)$ and 1,25-dihydroxyvitamin $\mathrm{D}(3)$. Cancer Res 65:493-498

30. Geibel J, Sritharan K, Geibel R, Geibel P, Persing JS, Seeger A, Roepke TK, Deichstetter M, Prinz C, Cheng SX, Martin D, Hebert SC (2006) Calcium-sensing receptor abrogates secreta- gogue- induced increases in intestinal net fluid secretion by enhancing cyclic nucleotide destruction. Proc Natl Acad Sci USA 103:9390-9397

31. Ogata H, Ritz E, Odoni G, Amann K, Orth SR (2003) Beneficial effects of calcimimetics on progression of renal failure and cardiovascular risk factors. J Am Soc Nephrol 14:959-967

32. Odenwald T, Nakagawa K, Hadtstein C, Roesch F, Gohlke P, Ritz E, Schaefer F, Schmitt CP (2006) Acute blood pressure effects and chronic hypotensive action of calcimimetics in uremic rats. J Am Soc Nephrol 17:655-662

33. Piecha G, Kokeny G, Nakagawa K, Koleganova N, Geldyyev A, Berger I, Ritz E, Schmitt CP, Gross ML (2008) Calcimimetic R568 or calcitriol: equally beneficial on progression of renal damage in subtotally nephrectomized rats. Am J Physiol Renal Physiol 294:F748-F757 